\title{
O papel da incerteza no planejamento de sistemas de educação a distância
}

Marianne Kogut Eliasquevici

Arnaldo Corrêa Prado Junior

Universidade Federal do Pará

\section{Resumo}

A tarefa de projetar um sistema de educação a distância (SEAD) é um processo complexo devido ao número de componentes envolvidos, às diferentes visões e abordagens quanto à sua eficácia, aos valores em disputa, aos interesses em jogo e às decisões urgentes. Este trabalho, partindo da experiência constante de livros e artigos dos autores, faz um recorte na tese de doutoramento de um deles a fim de descrever a importância da análise de incertezas em programas de educação a distância, o que se acredita levar à redução da probabilidade de ocorrência de eventos indesejáveis e/ou inesperados em várias situações caracterizadas por ambientes complexos. Descreve-se a trajetória da incerteza na perspectiva da ciência e apresenta-se um referencial teórico para dar suporte à temática do planejamento de SEADs. São citadas, também, as formas como as incertezas podem incidir nos processos decisórios e de implantação de SEADs, tomando por base uma pesquisa realizada no estado do Pará. Estratégias foram especificadas na perspectiva de melhorar a articulação entre as iniciativas das diversas áreas, de modo a potencializar a participação dos diferentes atores e reforçar o papel da educação a distância como política pública para a inclusão social. Nas considerações finais, reforça-se a adaptabilidade da investigação para outras situações. 0 trabalho pretende ser uma contribuição na indicação de diretrizes estratégicas para subsidiar a implantação de SEADs.

\section{Palavras-chave}

Educação a distância - Planejamento - Gerenciamento de incerteza.

\section{Correspndência:}

Marianne Kogut Eliasquevici Faculdade de Computação Inst. de Ciências Exatas e Naturais Av. Augusto Corrêa, n. 1 66075-110 - Belém - PA e-mail: mariane@ufpa.br 


\section{The role of uncertainty in planning systems of distance education}

Marianne Kogut Eliasquevici

Arnaldo Corrêa Prado Junior

Universidade Federal do Pará
Contact:

Marianne Kogut Eliasquevici

Faculdade de Computação

Inst. de Ciências Exatas e Naturais

Av. Augusto Corrêa, n. 1

66075-110 - Belém - PA

e-mail: mariane@ufpa.br

\begin{abstract}
The task of planning a system of distance education (SDE) is a complex process due to the number of components involved, the different views and approaches as to their efficacy, the contending values, the interests at play, and the urgent decisions often needed. This work starts from the experience available in books and articles by the authors, and draws from part of the doctorate thesis of one of them, with the purpose of describing the importance of uncertainty analysis in programs of distance education, thereby contributing to reduce the probability of occurrence of undesirable and/or unexpected events in various situations characterized by complex environments. It describes the trajectory of uncertainty in the perspective of science, and presents a theoretical framework to give support to the problem of planning SDEs. It also mentions the ways in which uncertainties can enter decision processes and the setting up of SDEs, taking as its source a study carried out in the State of Pará. Strategies were devised with a view to improve the articulation of initiatives in the various areas involved, in order to maximize the participation of the different actors and to reinforce the role of distance education as a public policy for social inclusion. In its final considerations, the article emphasizes the applicability of this investigation to other situations. The work aims at contributing to define strategic guidelines for the implementation of SDEs.
\end{abstract}

\section{Keywords}

Distance education - Planning - Uncertainty management. 
Um sistema de educação a distância (SEAD) consiste, segundo Moore e Kearsley (1996), de todos os componentes do processo que o formam, incluindo aprendizagem, ensino, comunicação, design, gerenciamento e mesmo alguns não tão óbvios como história e filosofia institucional. Um sistema pode ser o processo de Educação a Distância (EaD) de uma instituição, um programa, uma unidade, um consórcio ou somente um curso a distância.

EaD é, em primeira instância, educação. A decisão de projetar e implementar qualquer sistema passa a ser uma decisão política. Mesmo que a vontade, a instalação física, a contratação de recursos humanos, entre outros, sejam elementos importantes, não são suficientes. É preciso, também, coerência entre o que se requer e o que se tem, por meio do conhecimento da realidade na qual o processo está inserido e de suas limitações e políticas claras traduzidas em planos e programas viáveis. 0 sucesso de projetos de EAD é dependente da concepção de planejamento e administração envolvidas no processo.

A dificuldade na decisão e implementação de um SEAD torna-se evidente quando se observam a complexidade e o elevado número de componentes envolvidos: estudantes, corpo docente, professores-tutores, equipe técnica, instituição de ensino e infra-estrutura. Some-se a isso uma das características essenciais do processo de tomada de decisão que é a quantidade e a qualidade de informações disponíveis. 0 processo de tomada de decisão em EaD, tal como qualquer processo decisório, é feito diante de riscos e incertezas.

Por abordagem de sistemas, entende-se: uma forma de pensamento em termos de conexão, relacionamentos e contexto. De acordo com essa visão, as propriedades essenciais de um organismo, da sociedade ou de outro sistema complexo são propriedades do todo, que surgem das interações e dos relacionamentos entre as partes. As propriedades das partes não são intrínsecas, mas podem ser entendidas somente dentro do contexto do todo maior (Gallopín et al., 2001).

A definição de sistemas complexos não é trivial. Muitas vezes, são tratados somente como um paradigma contrário ao reducionismo, que surge com o aumento do número de elementos e/ou relacionamentos no sistema. Funtowicz e Ravetz (2002) observam que existem diferentes definições de complexidade, todas se associando, derivadas das várias áreas de prática científica. Gallopín et al. (2001) especificam alguns dos atributos presentes em sistemas complexos. Entre eles, por estarem presentes nos sistemas de EaD, pode-se citar: multiplicidade de perspectivas legitimadas, pela dificuldade de entender um sistema adaptativo sem também considerar o seu contexto; auto-organização, fenômeno pelo qual componentes que se interagem cooperam para produzir estruturas e comportamentos coordenados em larga escala; incertezas irredutíveis que surgem em sistemas complexos devido ao aparecimento de muitas fontes de origem.

Nesse sentido, um importante estágio para se tomar uma decisão contextualizada é gerenciar as incertezas inerentes ao problema, não as ignorando, encobrindo-as ou escondedoas. Saber administrar as incertezas passa pela aceitação ou acomodação delas, o que implica uma etapa anterior de dimensionamento e classificação destas (Corrêa, 1996). A tomada de decisão é muito mais do que o momento final da escolha, sendo um processo complexo de reflexão, investigação e análise, e o volume de informações e dados colocados à disposição do decisor deve ser na medida certa (Moresi, 2000).

Este trabalho, partindo da experiência constante de livros e artigos dos autores (Eliasquevici; Fonseca, 2004; Prado Jr., 2001), faz um recorte na tese de doutoramento de Eliasquevici (2005) a fim de descrever a necessidade da análise de incertezas em programas de EaD. Inicialmente descrevese a trajetória da incerteza para que se compreenda a sua importância para o conhecimento científico. Um referencial teórico, que subsidie a temática do planejamento de SEADs com suas especificidades e dificuldades, é apresentado no tópico seguinte. Em seguida, são citadas as formas como as incertezas podem incidir nos processos decisório e de implantação de SEADs, tomando por base uma pesquisa realizada no estado do Pará. Nas consi- 
derações finais, reforça-se a adaptabilidade da investigação para outras situações.

\section{A incerteza numa perspectiva da ciência}

0 pensamento científico passou por várias mudanças paradigmáticas, de forma a tornar possível a compreensão da existência da incerteza e do seu tratamento. Razões para essas mudanças podem ser encontradas nas discussões epistemológicas ocorridas entre os séculos XVIIl e XX, a partir do período conhecido como lluminismo com a construção de idéias que fundamentam transformações sociais, econômicas e políticas relacionadas a uma nova compreensão de mundo.

De acordo com Suassuma (1999), o projeto iluminista foi o ideário da modernidade, época marcada pela revolta contra o poder da lgreja, do rei e da aristocracia e pelo início das discussões dos direitos humanos. Os filósofos iluministas acreditavam que o próprio indivíduo poderia encontrar respostas às suas perguntas, buscando, no início, inspiração na lógica carte-siana segundo a qual o homem deveria estar dividido em corpo e espírito. Somente quando a razão e o conhecimento se fundissem é que a humanidade faria grandes progressos - o desenvolvimento material e moral do homem pelo Conhecimento. A razão era uma dádiva da natureza ao homem.

A objetividade da modernidade se distancia de Descartes com o sistema newtoniano, que rompe com o pensamento de uma natureza oculta e insondável. "A natureza se transforma em um sistema de leis matemáticas estabelecidas por um Deus racional. A razão não se acomoda à contradição, e desta forma, a verdade científica/racional é, em essência, indubitável [...]" (Becker; Gomes, 1993, p.150). A natureza e a sociedade ficam então submetidas aos mesmos mecanismos e às mesmas relações de causa e efeito.

0 movimento iluminista trouxe consigo o ideal da investigação sistemática, a matematização da experiência, isto é, a utilização de métodos matemáticos quantitativos que levariam ao conhecimento seguro e certo da realidade.
No século XIX, surge o Positivismo, de Augusto Comte, que tinha como pressupostos a criação de leis universais, a ordem e o progresso. Essa doutrina acreditava ter ultrapassado o estágio do conhecimento teológico e o metafísico por um saber definitivo científico ou positivo. 0 Positivismo é um procedimento teórico-metodológico de entendimento dos fenômenos sociais sob o mesmo prisma com que são entendidos os fenômenos naturais. É reflexo das novas idéias instituídas pelo lluminismo que, por sua vez, fundamenta a modernidade. Nessa época, o método quantitativo das ciências naturais era a abordagem adotada para se alcançar o conhecimento objetivo. A incerteza era algo considerado como não científico.

Embora os valores positivistas fossem dominantes ao longo do século XIX e início do XX, seus princípios epistemológicos sempre estiveram sendo questionados. Entretanto, para Van Asselt e Rotmans (2000), a primeira grande crise do Positivismo foi originada na Matemática, quando contradições nos princípios lógicos desta foram reveladas no início do século XX. Einstein teve um papel importante com a proposta de uma nova Física (teoria da relatividade). A emergência da Estatística intensificou o estudo da incerteza. 0 princípio da incerteza de Heisenberg na década de 30 do século XX foi significante nesse processo.

Além da Matemática e da Física, manifestações em outras áreas também começavam a traduzir a insatisfação com o modelo positivista da ciência (Biologia: Humberto Maturana e Francisco Varela; Teoria geral dos sistemas: Ludwig von Bertalanffy; Cibernética: Norbert Wiener; etc.). 0 reflexo desse movimento foi a percepção da ciência como não puramente objetiva e de que o conhecimento não é equivalente à verdade e certeza, considerando a existência de incertezas fundamentais que não podem ser reduzidas por meio de mais pesquisas.

Logo, no dizer de Morin (2001):

A MAIOR CONTRIBUIÇÃO de conhecimento do século XX foi o conhecimento dos limites do conhecimento. A maior certeza que 
nos foi dada é a da indestrutibilidade das incertezas, não somente na ação, mas também no conhecimento. (p. 55)

Cresce a necessidade de uma revisão dos modelos que movem a ciência à medida que a realidade se complica, que as transformações se aceleram, que as incertezas se expandem e que um aumento notável nos riscos perpassa à humanidade.

Uma relevante perspectiva transdisciplinar para o estudo de problemas complexos vem sendo desenvolvida por autores que defendem a necessidade de reestruturação das práticas científicas, por meio da proposição do que consideram "ciência pós-normal". Funtowicz e Ravetz (2002), seus idealizadores, afirmam que a ciência pós-normal é uma forma de expressar apropriadas estratégias para solução de problemas, focando nos aspectos que tendem a ser negligenciados pelas tradicionais práticas científicas, quais sejam: existência da incerteza, valores em jogo e uma pluralidade de perspectivas legítimas. 0 "pósnormal" significa ir além do normal, no sentido de que os procedimentos usuais baseados na ciência "normal" (Kuhn, 1978) não são suficientes, ainda que permaneçam indispensáveis para nortear o processo de tomada de decisão.

\section{Planejamento de sistemas de EaD}

Durante o processo de implantação de SEADs, alguns questionamentos antigos, aparentemente já respondidos, ainda podem vir à tona dependendo do perfil do planejador: i) quais são os elementos que se precisa considerar em projetos de EaD? ii) quais são os fatores que colocam em risco a implantação? iii) quais são os diversos entendimentos que se têm do assunto? iv) qual é o tamanho da demanda? v) que meios utilizar? vi) qual o papel dos governantes? vii) quais são as expectativas concernentes aos resultados? Essas perguntas, quando extrapoladas para um futuro que não é conhecido, acabam por gerar incertezas no processo. Causas dessas incertezas residem na variabilidade do sistema e no desconhecimento de alguns dos mecanismos de interconexões entre os componentes de um sistema de EaD. Além do mais, existem também as incertezas referentes aos objetivos da EaD e suas possíveis contribuições. A EaD pode, então, ser tratada como uma modalidade educativa que traz consigo dúvidas e incertezas.

0 insucesso de programas muitas vezes bem intencionados pode resultar do fato de não terem sido consideradas as incertezas que permeiam o processo (divergências de opinião, juízos de valor, entre outros). Contradições sobre a temática se justificam pelos diferentes comportamentos dos participantes e interessados, que acabam por influenciar o rumo tomado pelos projetos. As incertezas ocorrem principalmente devido ao nosso incompleto conhecimento e a um equivocado entendimento dos processos sociais, econômicos e ecológicos. Aparecem como resultado de juízo de valor, ausência de informação, informação inadequada, divergência de opinião, dados incompatíveis e variabilidade do sistema.

A ausência de dados e informações não é a única origem das incertezas. Existem também condicionantes socioculturais. 0 comportamento humano é imprevisível e, sendo assim, o comportamento dos diferentes atores sociais e suas políticas também são incertos. Inovações tecnológicas e a percepção destas pelos usuários também possuem influência na EaD, o que pode tornar o processo mais complexo e mais difícil de predizer. Casas Armengol (1987) atenta para a necessidade de se contar com um sistema principal de decisões interconectadas para que se possa alcançar os objetivos sociais.

0 tomador de decisão deve tornar-se mais hábil para lidar com mudanças contínuas, visando enfrentar com mais conhecimento situações desfavoráveis surgidas durante o processo. Nesse sentido, o primeiro passo para se tomar uma decisão é gerenciar as incertezas inerentes ao problema.

García Aretio (2001) apresenta cinco objetivos e motivações que levam instituições e governos a investirem nessa modalidade educa- 
cional: i) democratizar o acesso à Educação; ii) propiciar uma aprendizagem autônoma e ligada à experiência; iii) investir em um ensino inovador e de qualidade; iv) fomentar a educação permanente; e v) reduzir os custos.

Por seus objetivos sociais e ante as possibilidades de ampliação de fontes de receita, vê-se uma proliferação da oferta de cursos, como se fosse algo fácil de ser implementado. Todavia, no dizer de Lobo (2000):

Muitas vezes projetos de educação a distância sofreram severos desgastes em razão de falsas concepções; adesões precipitadas a novidades sofisticadas; açodamento no diagnosticar realidades, no estabelecer viabilidades, no eleger prioridades. (p. 10)

Essa afirmação corrobora a necessidade do planejamento como ferramenta imprescindível na tomada de decisão sobre implantação e uso da modalidade, envolvendo tanto a visão estratégica do cenário no qual se pretende atuar como da complexidade do processo, de forma a suplantar a improvisação, a oferta de programas inadequados e a insuficiente visão de limites.

Enquanto no sistema presencial de ensino a gestão se volta para uma população relativamente estável e numericamente previsível condicionada à estrutura física e aos recursos humanos e materiais existentes, na EaD, a ges- tão depara-se com processos e dimensões nem sempre previsíveis. Portanto,

[...] a exata compreensão do conjunto de variáveis, funções e interconexões entre as estruturas educativas e os sistemas sociais requer a utilização adequada do planejamento, da investigação e das modernas teorias sobre organização, administração e tomada de decisão. (Casas Armengol, 1987, p. 120, tradução nossa)

São vários os fatores que podem afetar o planejamento, ressaltando-se as taxas de crescimento da demanda, a diversidade do mercado, as tendências políticas e culturais, a legislação, as iniciativas governamentais, o desenvolvimento tecnológico, a evolução das mídias, a filosofia e capacidade institucional (pública, privada ou empresarial), as perspectivas de trabalho para os estudantes, a elevação dos custos envolvidos e as diversas possibilidades de demandas formativas.

Os gestores de EaD devem conhecer claramente as características e demandas do seu público-alvo, quer sejam pessoas físicas ou empresas, de forma a poder planejar o quanto necessitarão investir antes da oferta de qualquer curso a distância. Há que se ter ciência dos componentes básicos de um SEAD para que se possa distingui-los dos análogos em sistemas presenciais. Moore e Kearsley (1996) consideram que o modelo sistêmico provê uma ferra-

Quadro 1: Componentes de um sistema de EaD.

\begin{tabular}{|l|l|}
\hline Subsistemas & Característica \\
\hline Estudante & $\begin{array}{l}\text { Elemento básico e destinatário de todo fazer educativo em cursos a distância: normalmente são pessoas adultas. 0 fato de 0 } \\
\text { estudante realizar grande parte do aprendizado a distância requer metodologias diferenciadas. }\end{array}$ \\
\hline Docente & $\begin{array}{l}\text { A eficiência e a eficácia das instituições educativas dependem em grande parte da formação, capacidade e atitude de seus } \\
\text { docentes. Em cursos a distância, a ação docente aparece mais complexa devido à multiplicidade de agentes que intervêm desde } \\
\text { o projeto do curso até a avaliação da aprendizagem dos alunos. }\end{array}$ \\
\hline $\begin{array}{l}\text { Comunicação } \\
\text { através dos meios }\end{array}$ & $\begin{array}{l}\text { A comunicação completa (emissor, receptor, mensagem, canal e feedback), bidirecional, é a requerida para a educação de } \\
\text { forma geral e também para a EaD em particular. }\end{array}$ \\
\hline $\begin{array}{l}\text { Estrutura, } \\
\text { organização e } \\
\text { gestão }\end{array}$ & $\begin{array}{l}\text { Além de contar com todas as unidades e funções semelhantes às de instituições presenciais (matrícula, informação, inscrição e } \\
\text { outros), deve dispor também de: i) unidade de projeto e produção de materiais; ii) unidade de distribuição de material; iii) } \\
\text { processo de comunicação; iv) coordenação do processo de aprendizagem; v) avaliação; e vi) centros ou unidades de apoio } \\
\text { dispersos da matriz de forma a atender os alunos. Sobre a estrutura administrativa, Cordero (2004) ressalta que esta deve ser } \\
\text { mais reforçada do que as de instituições tradicionais pelo fato de 0 aluno a distância não dispor de tempo para ir à instituição } \\
\text { resolver problemas. }\end{array}$ \\
\hline $\begin{array}{l}\text { Outros } \\
\text { componentes } \\
\text { menos especificos }\end{array}$ & \begin{tabular}{l} 
i) missão; ii) programas e currículos; iii) técnicas e estratégias de ensino; e iv) relação entre os alunos. \\
\hline
\end{tabular}
\end{tabular}

Fonte: adaptado de García Aretio (2001). 
menta que não somente auxilia a reconhecer muitos dos itens que separam a EaD da educação convencional, como também permite distinguir entre bons e maus projetos. Para García Aretio (2001), os componentes, que também podem ser considerados como subsistemas da EaD, estão representados no Quadro 1.

No caso de instituições de Ensino Superior, na hora de demarcar o quadro institucional, os planejadores se deparam com várias situações, cada uma com características próprias: i) a instituição é criada somente para ofertar cursos na modalidade a distância (ex.: Open University/lnglaterra); ii) a modalidade é integrada a uma instituição tradicional de ensino (misto): esta tem sido a forma mais freqüentemente implementada; e iii) ofertada em rede ou consórcios reunindo especialistas de diversas instituições em regime de cooperação.

As ações de EaD requerem que se tome uma série de decisões de forma ágil e estrategicamente pertinente. Na literatura, não são facilmente encontradas referências concretas sobre como fazê-las, principalmente quando se precisa mapear fatores subjetivos, tais como divergência de opinião, tendências culturais, diferenças de entendimento. Somados a outros, esses fatores geram incertezas implícitas e explícitas que perpassam o processo de tomada de decisão e, se não forem trabalhadas, podem resultar em problemas, dificuldades e resistências futuras.

Como conseqüência, o uso de um enfoque sistêmico e integrado representa um tipo de metodologia útil para o estudo, design e implementação especialmente de SEADs que estão sendo constantemente influenciados pelo meio social em que se encontram. $\mathrm{Na} \mathrm{EaD,} \mathrm{existem} \mathrm{fa-}$ tos tipicamente incertos, valores em disputa, interesses em jogo que exigem decisões urgentes. Esses fatos tornam o problema de implantação de sistemas de EaD não apenas meramente complicados. Eles envolvem uma variedade de subsistemas e não somente um simples ponto de vista para sua análise.

A implantação de SEADs, de acordo com Casas Armengol' (1987), dependerá rigorosamente dos resultados obtidos por meio de um conjunto de passos sintetizados no fluxograma a seguir:

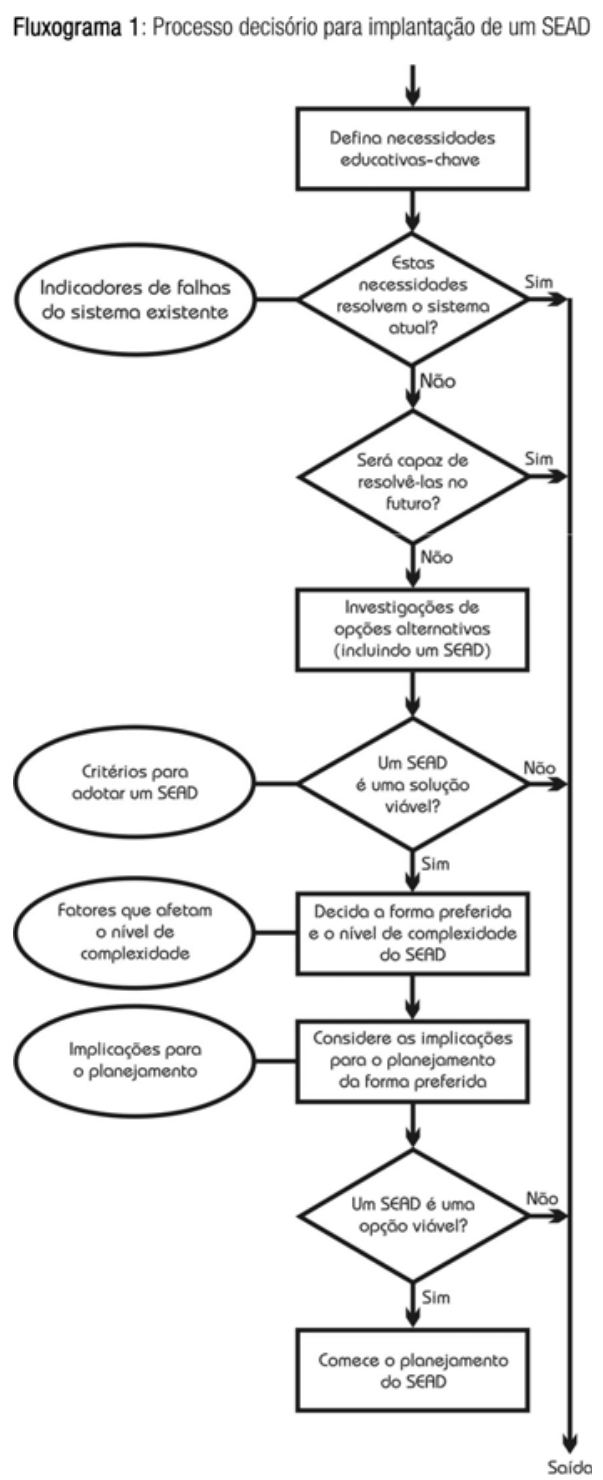

Fonte: adaptado de Casas Armengol (1987)

Em cada uma das etapas do processo decisório, podem se materializar incertezas, problemas, temores e dúvidas.

1. Casas Armengol (1987) está se referindo à implantação de SEADs para educação superior como ação de uma política pública governamental. Por exemplo: a criação de universidades abertas e a distância. Todavia, estes passos serão utilizados de forma abrangente para o processo decisivo de implantação de um sistema de EaD. 


\section{Problemas, dificuldades, resistências e temores}

Conforme Litto (2004?), o setor educacional que mais cresce no mundo é o da aprendizagem a distância e o Brasil, quando comparado a outros países, está atrasado, em parte, por não considerar a demanda reprimida do Ensino Médio e Superior. Ainda não há um consenso sobre qual o melhor modelo de estruturar a EaD no país de forma a atender a nossa realidade. Também não estão completamente definidas questões como propriedade intelectual, tecnologias disponíveis e o público prioritário que merece ser considerado. A carência na elaboração acadêmica proativa, que muitas vezes leva a um sentimento de fracasso, na visão de Barcia e Vianney (1998), transcende a organização e o gerenciamento de sistemas de EaD por envolver mudanças conceituais e comportamentais arraigadas na educação formal e na cultura brasileira.

Embora as experiências em EaD não sejam recentes, continua prevalecendo a necessidade de se lutar contra os preconceitos existentes. Conforme o dizer de Garcia (2000):

Em muitos ambientes ela [EaD] é vista como um facilitário pedagógico para quem não deseja fazer muito esforço para regularizar sua situação escolar ou como uma educação de segunda categoria para os pobres que não podem (ou não devem) aspirar a uma escolarização de melhor qualidade. Tanto num caso como em outro o preconceito se revela na admissão de que deve existir um tipo de educação para as elites e um outro para os pobres, que devem se contentar com modelos alternativos de pouca expressão e de baixa valorização social. (p. 82)

Constata-se um descompasso entre as barreiras existentes para a implementação de bons programas de EaD e os seus objetivos. Há morosidade em especial pelo desconhecimento de suas potencialidades. Soma-se a isso o receio pelo que é novo. Dificuldades, barreiras e obstáculos retirados da literatura que tendem a limitar a expansão da EaD são de diversos tipos. Aqueles considerados mais proeminentes foram categorizados conforme descrito no Quadro 2.

Deve-se evidenciar que muitas dessas dificuldades são circunstanciais, já que, superando o desconhecimento e a falta de empenho por parte dos planejadores e gestores, estas podem ser mitigadas ou até mesmo sanadas. Conhecer o que pensam os diversos atores sobre a EaD e classificar e localizar como essas opiniões afetam o planejamento de SEADs é uma etapa importante para se implementar estratégias de amenizar as incertezas existentes.

Quadro 2: Problemas, dificuldades e resistências.

\begin{tabular}{|c|c|c|c|c|}
\hline Divergências e objetivos & Metodológicas & Politicas e planejamento & $\begin{array}{l}\text { Comportamento, atitudes e } \\
\text { preconceitos }\end{array}$ & Tecnológicas \\
\hline $\begin{array}{l}\text { - Desconhecimento do que seja } \\
\text { EaD; } \\
\text { - Interesses particulares se } \\
\text { contrapondo à realização dos } \\
\text { objetivos propostos; } \\
\text { - As pessoas que desejam as } \\
\text { mudanças nem sempre fazem } \\
\text { parte do processo de } \\
\text { planejamento e tomada de } \\
\text { decisão; } \\
\text { - Ausência de visão compartilhada } \\
\text { sobre EaD na organização. }\end{array}$ & $\begin{array}{l}\text { - Medição e aferição das } \\
\text { reais contribuiçōes para o } \\
\text { aprendizado e para a vida; } \\
\text { - Barreiras lingüisticas e } \\
\text { culturais; } \\
\text { - Transição direta, sem as } \\
\text { adaptações necessárias da } \\
\text { modalidade presencial para } \\
\text { a distância; } \\
\text { - Taxas de evasão e } \\
\text { conclusão como únicos } \\
\text { critérios para se avaliar o } \\
\text { fracasso ou sucesso de um } \\
\text { curso; } \\
\text { - Aumento na carga de } \\
\text { trabalho docente, que } \\
\text { ainda nāo está preparado } \\
\text { adequadamente para tal. }\end{array}$ & $\begin{array}{l}\text { - Utilização de modelos } \\
\text { antigos para desenvolver } \\
\text { novas políticas; } \\
\text { - Ausência de suporte; } \\
\text { - Questōes de propriedade } \\
\text { intelectual sobre o material } \\
\text { didático; } \\
\text { - Competitividade entre } \\
\text { cursos presenciais e a } \\
\text { distância na mesma } \\
\text { instituiçãa; } \\
\text { - Inexistência de critérios e } \\
\text { indicadores de avaliação } \\
\text { sistemática dos projetos; } \\
\text { - Ausência de } \\
\text { financiamento; } \\
\text { - Desconhecimento da } \\
\text { demanda e público-alvo; } \\
\text { - Ausência de recursos } \\
\text { humanos capacitados. }\end{array}$ & $\begin{array}{l}\text { - Exigência de mudanças de } \\
\text { hábitos e posturas; } \\
\text { - Ausência de prestígio profissional } \\
\text { para os que se formam; } \\
\text { - Tomadores de decisão acham } \\
\text { necessário, mas não acreditam; } \\
\text { - Professores universitários nem } \\
\text { sempre aceitam a substituição de } \\
\text { uma estrutura já conhecida por } \\
\text { outra ainda não totalmente } \\
\text { aprovada. }\end{array}$ & $\begin{array}{l}\text { - Pouca familiaridade com } \\
\text { o uso das novas } \\
\text { tecnologias de } \\
\text { informação e } \\
\text { comunicação; } \\
\text { - Uso inadequado da } \\
\text { tecnologia; } \\
\text { - Limitação do uso da } \\
\text { Internet em face da } \\
\text { infra-estrutura existente, } \\
\text { possuindo um caráter } \\
\text { elitista. }\end{array}$ \\
\hline
\end{tabular}




\section{Incertezas e sua pressão no processo de planejamento e operacionalização de SEADs}

0 referencial teórico até agora exposto se apóia no reconhecimento da importância da incerteza no contexto do planejamento e da tomada de decisão. Foi com essa perspectiva que se procurou, a partir de um estudo de campo (Eliasquevici, 2005), verificar de que forma isso ocorre para os SEADs. Durante os anos de 2003 e 2004 , foram realizados vários procedimentos metodológicos de pesquisa (questionários, método de inquérito delplhi e entrevistas fonadas) com indivíduos envolvidos com a EaD no Pará.

Dada a dinamicidade do processo, do momento em que os dados foram coletados até a data em que este artigo foi escrito, acredita-se que mais experiências e projetos possam estar sendo encaminhados. Mesmo assim, os resultados constatados, ainda que não representem toda a gama de experiências, servem para direcionar novos trabalhos ao traçar possíveis indicativos do que está acontecendo no estado.

Quando os gestores de instituições públicas e privadas foram questionados sobre quais as dificuldades para implantação da EaD no Pará, verificou-se que entre as mais presentes estão: a insuficiência de recursos financeiros, a carência de recursos humanos qualificados e a deficiência na infra-estrutura tecnológica e de telecomunicações. Quanto aos motivos para ampliar a modalidade no estado, a superação das dificuldades geográficas, a democratização do acesso e a expansão do conhecimento foram os mais destacados. Com relação às incertezas presentes no processo de EaD, do ponto de vista dos gestores, a questão sociocultural é mais forte, com ênfase para a credibilidade.

Num segundo momento da pesquisa, foi utilizado o método de inquérito delphi, em três rounds, para entender a visão de outros atores sobre EaD, de forma a identificar as incertezas mais relevantes que precisam ser consideradas pelos tomadores de decisão na hora de planejar os diversos SEADs. Após aceitar participar do delphi, um questionário foi distribuído aos painelistas (e-mail, correio, pessoalmente) ${ }^{3}$, contendo uma pergunta aberta solicitando que listassem, baseados na experiência pessoal, até dez incertezas que consideravam presentes na utilização da EaD pelo sistema educacional do Pará. Reunindo as incertezas pela semelhança ou associação, foram categori-zadas 44 incertezas, sendo que somente oito apresentaram o consenso sobre a importância atribuída igual a 5 (relevância "muito grande") ou 4 (relevância "grande"), retratando dúvidas pertinentes à eficácia do processo, avaliação, qualidade da aprendizagem, condições infra-estruturais do estado, tutoria, materiais didáticos e acesso aos recursos tecnológicos.

Devido ao baixo consenso quanto ao grau de relevância atribuída como "grande" e "muito grande", mesmo que para a maioria dos respondentes todas as incertezas fossem relevantes, e ao elevado número de incertezas inventariadas durante o processo, para enriquecer os resultados provenientes do delphi, foi utilizada a técnica estatística de análise de cluster.

Para agrupar as 44 incertezas e elaborar a matriz de distâncias, foi empregado o coeficiente de correlação Phi, pois, de acordo com Oliveira (2005), quando se agrupam variáveis, o ideal é que se possa utilizar uma medida de correlação. No caso de variáveis que assumem valores 0 e 1 (dummies), pode ser utilizado o coeficiente de correlação Phi. Para a formação dos grupos, estes foram interrompidos em um nível de similaridade de 0,34 , resumindo as 44 incertezas em oito conjuntos de controvérsias, descritos no Quadro 3.

2. 0 delphi trabalha com a opinião de pessoas especialistas e/ou interessadas na área do estudo, para investigar as convergências e divergências de opiniões entre os participantes estabelecendo-se três condições básicas: 0 anonimato dos respondentes, a representação estatística da distribuição dos resultados e o feedback de respostas do grupo para reavaliação nas rodadas subseqüentes. Trata-se de um questionário interativo, que circula repetidas vezes pelo grupo que compõe o painel para que, ao final, se atinja o nível de consenso desejado. A cada nova rodada de questionário, as perguntas são repetidas, e os participantes podem reavaliar suas respostas à luz das respostas numéricas e das justificativas dadas pelos demais respondentes na rodada anterior.

3. Os painelistas que participaram da pesquisa foram alunos de graduação de Matemática a Distância, secretários municipais de Educação, coordenadores de projetos, tutores/professores e colaboradores. 


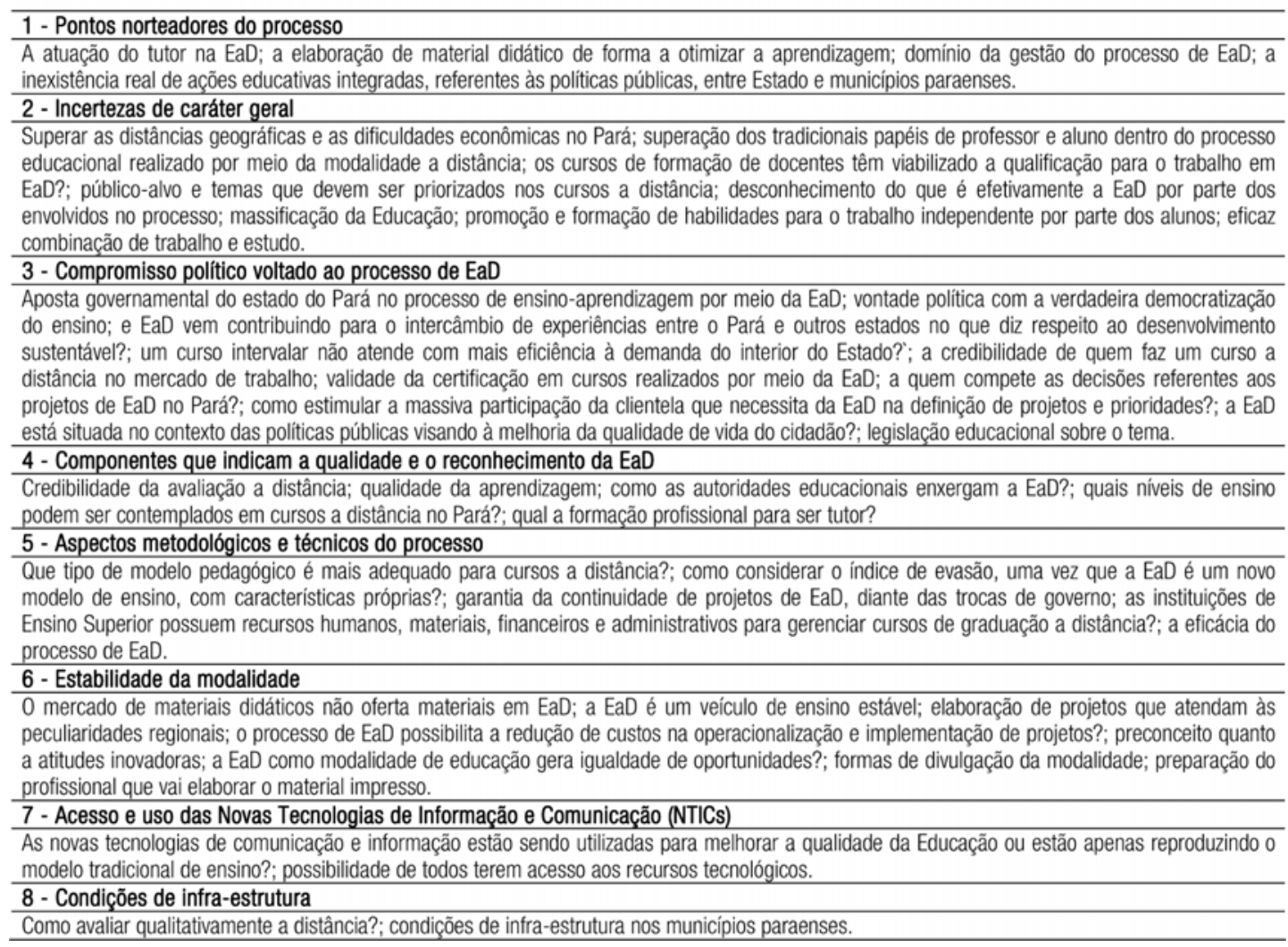

Diante dos resultados, percebe-se que a implantação de SEADs deve ser precedida por um processo decisório, tal como indicado por Casas Armengol (1987) no Fluxograma 1. Entretanto, quais critérios de decisão aplicar? Quais as incertezas que ocorrem nessa etapa do processo decisório? Como tomar uma decisão se a habilidade em prever o curso dos eventos é limitada? Pequenas alterações aparentemente isoladas de um fenômeno podem provocar mudanças amplas num sistema maior.

Uma das formas usadas para ajudar o tomador de decisão é a tentativa de antecipar o inesperado, identificando os fatores importantes e as origens dos obstáculos encontrados no problema. Morgan e Henrion (2004) argumentam que raramente os problemas são resolvidos em definitivo, porque estão sempre ressurgindo. Os detalhes podem mudar, mas as questões básicas continuam retornando. Algumas vezes, é fundamental valer-se de análises que já foram realizadas no passado ou adaptá-las, para apoiar a solução dos problemas do momento. Isso se torna mais fácil quando as incertezas do passado foram cuidadosamente descritas, pois se adquire uma maior confiança de que se utilizará um trabalho que foi realizado anteriormente de forma apropriada.

Com base nos oito conjuntos agrupados na pesquisa, nos critérios de decisão organizados por Morgan e Henrion (2004) e no fluxograma que representa o ato da decisão, propõe-se um novo fluxograma (Fluxograma 2), evidenciando os grupos de incertezas mais pertinentes para cada etapa da decisão e os critérios que podem ser empregados.

0 passo que envolve perguntar pela primeira vez se um SEAD é uma solução viável, como bem expõe Casas Armengol (1987), contempla um exame rigoroso da justificativa e da viabilidade desse sistema, seus critérios e pré-requisitos. Des- 


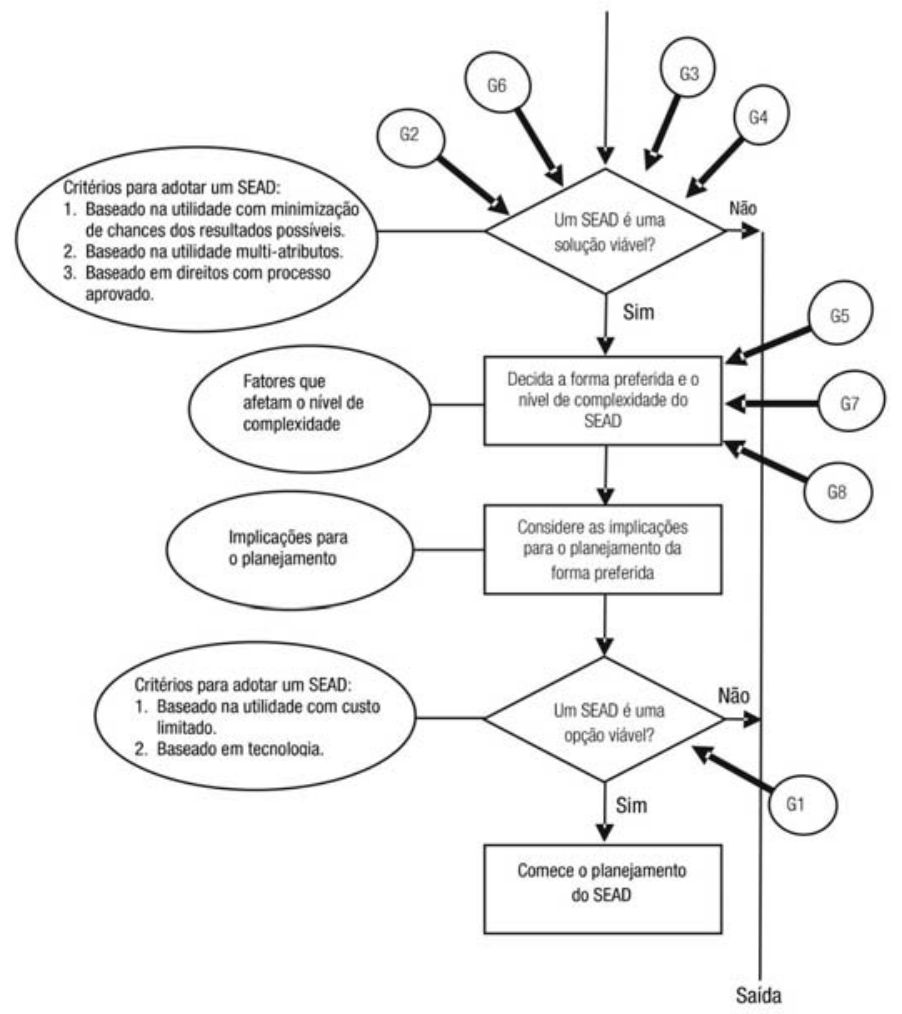

Legenda: G1: pontos norteadores do processo; G2: incertezas de caráter geral; G3: compromisso político voltado ao processo de EaD; G4: componentes que indicam a qualidade e o reconhecimento da EaD; G5: aspectos metodológicos e técnicos; G6: estabilidade da modalidade; G7: acesso e uso das NTICs; G8: condiçōes de infra-estrutura.

Fonte: Eliasquevici (2005) adaptado de Casas Armengol (1987).

sa forma, as incertezas de caráter geral (G2), o compromisso político (G3), os componentes que indicam a qualidade e o reconhecimento da EaD (G4) e a estabilidade da modalidade (G6) mostramse pertinentes à etapa, por demonstrarem a ocorrência de preconceitos, desconhecimento, compromisso político não claramente especificado e pouca credibilidade, fatores esses que incidem no receio de se arriscar em uma modalidade que ainda não está suficientemente estável. Nessa situação, os critérios que podem ser aplicados na análise do problema se fundamentam:

- Na utilidade com minimização de chances dos piores resultados possíveis: a existência de considerações política e comportamental induz ao uso desse critério. Uma vez indicada a opção pela modalidade de EaD e por ainda persistirem desconhecimento e preconceito, deve-se tentar minimizar as chances dos piores resultados.

- Na utilidade multiatributos: diante das dificuldades em utilizar valores monetários como base para a implantação, haja vista que existe a incerteza se com a EaD realmente é possivel uma redução de custos, pode-se pensar em avaliar os resultados em termos de outros atributos que não o monetário.

- Em direitos com processo aprovado: em face da ocorrência de diferentes interesses e expectativas, na ocasião de se estabelecer critérios de decisão, é essencial relevar as distintas análises que nem sempre convergem para um úni- 
co critério. Para que não haja uma pulverização e tampouco uma dispersão, é necessário reconhecer o ponto de vista das partes envolvidas e construir uma visão compartilhada a partir das sínteses que emanam dos consensos. Em algumas situações, o critério legal unifica as diferentes posições.

Feita a opção pelo SEAD, na etapa seguinte, são decididos a forma e o nível de complexidade que se pensa em adotar. Dentre os fatores que afetam a complexidade, estão questões tecnológicas, de infra-estrutura e aspectos que dizem respeito à metodologia. Por isso, é que se percebe a pressão dos grupos referentes aos aspectos metodológicos e técnicos do processo (G5), ao acesso e uso das NTICs (G7) e às condições de infra-estrutura (G8).

Seguindo os passos do fluxograma, diante da realidade apresentada ao tomador de decisão, este novamente se perguntará se um SEAD ainda é uma opção viável e, nesse momento, o grupo de incertezas denominado pontos norteadores do processo $(\mathrm{G} 1)$ exercerá pressão, pois levará o tomador de decisões a refletir sobre todos os pontos que ainda necessitam ser considerados para uma correta avaliação. Ele pode se valer de critérios fundamentados:

- Na utilidade com custo limitado: o tomador de decisões vivencia freqüentemente o problema da insuficiência de recursos orçamentários para desenvolver SEADs com todos os requisitos necessários aos subsistemas que os compõem. Acrescenta-se, ainda, a existência, na sociedade, de pessoas que não julgam pertinente ter como prioridade esse tipo de empreendimento. Assim, tentar fazer o melhor possível dentro das restrições orçamentárias pode ser um bom critério para impulsionar a realização e resguardar as possíveis críticas advindas da sociedade.

- Em tecnologia: a melhor tecnologia disponível, no contexto da EaD no Pará, segundo já mencionado, não significa a opção pelas NTICs, enfatizando a Internet. Uma boa aná- lise situacional, elaborada pelos tomadores de decisão, sugere a adoção de critérios que considerem não a tecnologia "mais atual", mas sim a possível, disponível e adequada.

\section{O planejamento da operacionalização}

Após passar por todas essas etapas, é dado início ao planejamento da operacionalização do SEAD. Esses mesmos conjuntos de incertezas reaparecem, pressionando também as etapas do planejamento, independentemente do modelo adotado ${ }^{4}$, conforme apresentado na Figura 1. Os resultados, no entanto, ganham similaridade com as teses do Planejamento Estratégico, enfatizando a sua vertente situacional, pois, diferentemente do planejamento tradicional, a realidade a ser planejada é apresentada ao dirigente ou planejador com a seguinte conformação: marcada pela complexidade e pelos conflitos, cheia de incertezas, caracterizada pela escassez de recursos, nenhum ator social tem hegemonia etc. (Costa, 2004). 0 planejamento é focado em problemas com cenários de previsão.

A Figura 1 retrata que durante a etapa de concepção são dois os grupos que exercem maior pressão: as incertezas de caráter geral (G2) e as condições de infra-estrutura (G8). Nessa fase, tornam-se mais evidentes os diversos jogos de interesse, pois a concepção é carregada de ideologias que, por sua vez, estão vinculadas aos objetivos e aos entendimentos que se têm do assunto.

Devido a essas diversas possibilidades, o grupo 2 (G2), pelas suas características, tende a pressionar essa etapa, uma vez que os obstáculos elencados demonstram fragilidade de entendimento de princípios básicos da EaD que necessitam estar bem esclarecidos no momento da concepção. Já o grupo 8 (G8) aponta a necessidade de conhecimento da infra-estrutu-

4. A linearidade das dimensões ou etapas é apresentada apenas do ponto de vista didático, por existir uma profunda ligação entre essas dimensões. 


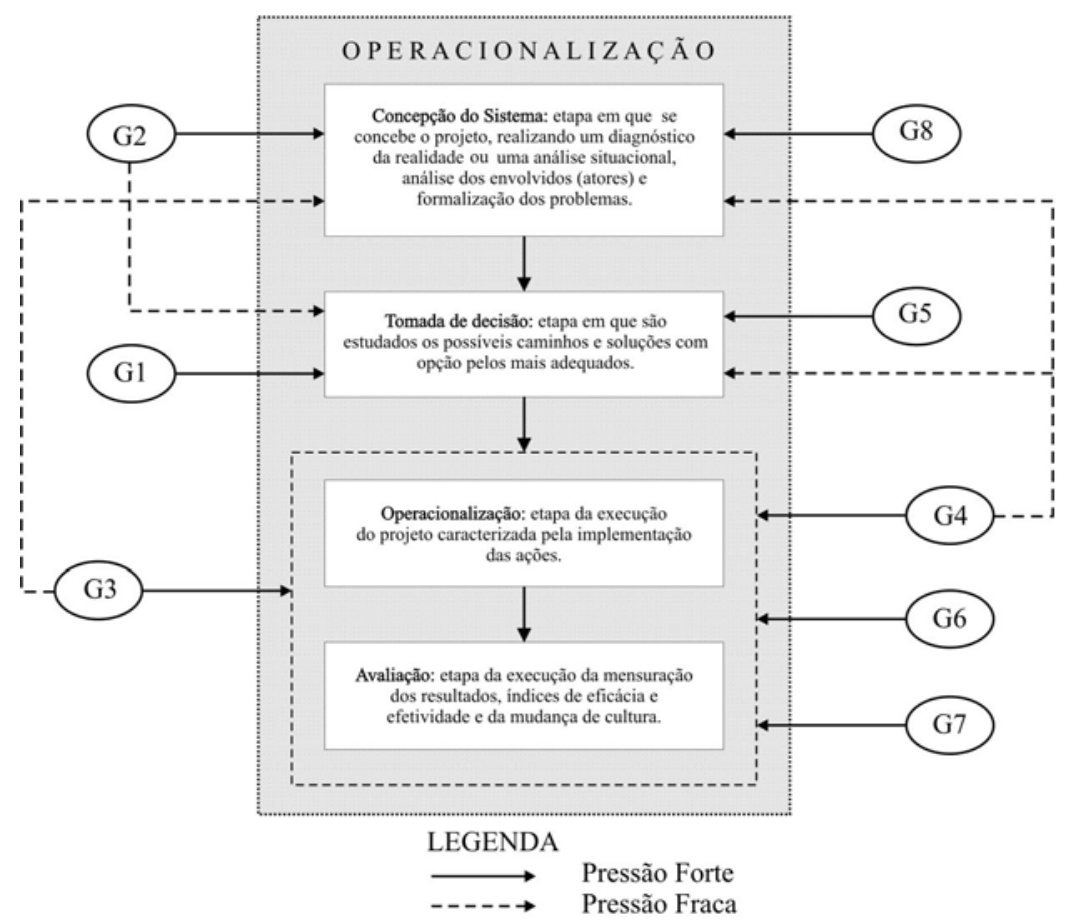

G1: pontos norteadores do processo; G2: incertezas de caráter geral; G3: compromisso político voltado ao processo de $\mathrm{EaD}$; $\mathrm{G} 4$ : componentes que indicam a qualidade e o reconhecimento da $\mathrm{EaD}$; $\mathrm{G5}$ : aspectos metodológicos e técnicos; G6: estabilidade da modalidade; G7: acesso e uso das NTICs; G8: condições de infra-estrutura.

Fonte: Eliasquevici (2005)

ra existente como parte do diagnóstico da realidade encontrada.

Na fase da tomada de decisão, os grupos relacionados aos pontos norteadores do processo (G1) e aos aspectos metodológicos e técnicos (G5) exercem maior pressão. Isso porque há necessidade de se estudar todas as possíveis soluções a serem utilizadas, o que implica o aparecimento de divergência de opiniões.

A etapa que contempla a operacionalização e avaliação é a que sofre mais incidência de grupos de incertezas. Entre os demais fatores, os erros acumulativos das etapas anteriores contribuem para essa situação. Os grupos referentes ao compromisso político (G3), aos componentes que indicam a qualidade e o reconhecimento da EaD (G4), à estabilidade da modalidade (G6) e ao uso e acesso às NTICs (G7) são os mais presentes nessa fase. Quanto mais estável a EaD, melhores condições de implementação de projetos. Para isso, o compromisso político que garanta as condições de efetivação da EaD juntamente com a qualidade tornam-se essenciais para mostrar que a modalidade é viável.

Todo dirigente que implementa sistemas de EaD almeja alcançar a efetividade e obter sucesso, e é a avaliação, propriamente dita, a fase que representa o esforço de mensurar a efetivi-dade do empreendimento. No que concerne à efetividade organizacional, Cameron (1978) retrata que definir critérios para medila é o maior obstáculo encontrado na análise empírica. Os problemas não são de ordem te- 
órica. A maioria das pessoas tem em mente alguma noção sobre o que valora como efetivo, porém essas noções são freqüentemente difíceis de operacionalizar (Cameron, 1976). Dessa forma, algumas questões precisam ser esclarecidas anteriormente ao processo de avaliação. Entre estas, destacam-se: i) sobre quais perspectivas a efetividade está sendo avaliada? ii) qual o propósito da avaliação? iii) que tipo de dados estão sendo coletados?

No caso específico da EaD, medir a efetividade e o sucesso pode envolver a abrangência geográfica, a relação custo/benefício, as questões acadêmicas, entre outras. 0 ideal é que seja uma combinação de vários fatores, o que torna a tarefa de mensuração dos resultados um trabalho complexo. A equipe de planejamento pode fazer uso de mecanismos que mesclam a avaliação formativa e a somativa. A avaliação formativa se refere à etapa que ocorre durante o processo de planejamento e desenvolvimento do projeto, incluindo as alterações que levem a possíveis mudanças de rumo. A avaliação somativa, por sua vez, envolve coletar, ao final do empreendimento, evidências que possam verificar a validade e a efetividade do projeto, incluindo critérios como taxa de evasão, mudanças de atitudes dos alunos, satisfação pessoal, mudança organizacional, sustentabilidade, taxa de retorno do empreendimento, benefícios profissionais etc. Cabe salientar que qualquer que seja o processo de avaliação dos resultados empregado, este deve ser elaborado por profissionais que entendam e conheçam as peculiaridades da modalidade da EaD, para não se incorrer no erro de mensurar a efetividade do sistema com base no sistema presencial.

Diante das razões ${ }^{5}$ e dificuldades ${ }^{6}$, apontadas pelos gestores para ampliar e implementar as ações de EaD no Pará, e dos grupos de incertezas que pressionam com intensidades diferentes a operacionalização de SEADs, é essencial estabelecer estratégias de redução, atenuação, acomodação ou superação dessas incertezas. Os Quadros 4 a 6 destacam essas estratégias por etapa do planejamento.
Os dirigentes têm sido forçados a tomar decisões sob um nível elevado de incertezas, o que requer habilidades de pensar e se relacionar interdisciplinarmente, implicando uma gestão proativa. Assim, todas as estratégias acima especificadas são sugeridas na perspectiva de melhorar a articulação entre as iniciativas das diversas áreas, de modo a potencializar a participação de todos os diferentes atores e reforçar a importância da EaD como política pública de inclusão social.

\section{Considerações finais}

Observa-se no Brasil que, dentre as políticas educacionais, programas de EaD estão na pauta da agenda governamental, e a discussão da modalidade como uma política pública de inclusão social envolve interesses diversos. A legislação está sendo revista e ampliada. Congressos, livros, artigos, enfim, a produção científica sobre o assunto se intensifica. Cursos com vários formatos são criados. Mesmo com esse panorama, ainda persistem dúvidas e preconceitos com relação à modalidade. No que diz respeito ao estado do Pará, a pesquisa de doutoramento detectou que a modalidade está ganhando força, a despeito das condições nem sempre satisfatórias (de recursos humanos; de infra-estrutura física, tecnológica e financeira; entre outras).

0 estudo foi realizado com o intuito de mostrar a versatilidade e usabilidade de se trabalhar com ferramentas que podem dar suporte à tomada de decisão, tendo como resultado informações capazes de gerar estratégias não somente em nível local, mas também regional ou nacional. A análise de incertezas pode ser aplicada em variadas escalas e situações, porém convém ressaltar que, por questões relacionadas a tempo e custos, os decisores nem sem-

5. Superação das dificuldades geográficas; democratização do acesso e a expansão do conhecimento; qualificação profissional; desenvolvimento regional; demanda reprimida para cursos presenciais.

6. Insuficiência de recursos financeiros; carência de recursos humanos qualificados; deficiência de infra-estrutura tecnológica e de telecomunicações; ausência de políticas públicas estaduais e municipais para EaD; insegurança quanto ao sucesso do investimento; desconhecimento das potencialidades da EaD. 
pre têm condições de executar um trabalho dessa amplitude.

Este artigo pretende ser uma contribuição sobre a necessidade e a importância da prática da gestão de incertezas no acompanhamento do pro- cesso decisório para que os planejadores possam se tornar mais ágeis e adaptáveis em diversas situações caracterizadas por ambientes complexos como programas governamentais que envolvem políticas públicas.

Quadro 4: Estratégias para a etapa de concepção do sistema

\begin{tabular}{|c|c|}
\hline Etapa & Concepcão do sistema \\
\hline Grupo de incertezas & Incertezas de caráter geral (G2) \\
\hline Estratégias & $\begin{array}{l}\text { a) buscar um compromisso mínimo de compreensão sobre a } \\
\text { modalidade que permita definir açōes e metas. } \\
\text { b) elaborar uma missão institucional para a EaD. }\end{array}$ \\
\hline Dificuldades/desafios & $\begin{array}{l}\text { - carência de recursos humanos qualificados; } \\
\text { - desconhecimento das potencialidades da EaD. }\end{array}$ \\
\hline Grupo de incertezas & Condiç̄es de infra-estrutura \\
\hline Estratégias & $\begin{array}{l}\text { a) implementar medidas que garantam condições mínimas } \\
\text { de infra-estrutura para suportar o desenvolvimento da modalidade, } \\
\text { considerando a necessidade de acesso aos recursos de forma equânime. } \\
\text { b) articular apoio logistico e operacional de empresas e instituições que } \\
\text { possuem capacidade de longo alcance (ex: exército, correios etc.). }\end{array}$ \\
\hline Dificuldades/desafios & - deficiência de infra-estrutura tecnológica e de telecomunicaçōes. \\
\hline
\end{tabular}

Quadro 5: Estratégias para a etapa de tomada de decisão

\begin{tabular}{|l|c|}
\hline \multicolumn{1}{|c|}{ Etapa } & \multicolumn{1}{c|}{ Tomada de decisão } \\
\hline Grupo de incertezas: & Pontos norteadores do processo (G1) \\
\hline Estratégias & $\begin{array}{c}\text { a) implementar medidas destinadas a ampliar a } \\
\text { compreensão dos envolvidos sobre a modalidade. }\end{array}$ \\
\hline Dificuldades/desafios & $\begin{array}{l}\text { - carência de recursos humanos qualificados; } \\
\text { - desconhecimento das potencialidades da EaD. }\end{array}$ \\
\hline Grupo de incertezas & Aspectos metodológicos e técnicos do processo (G5) \\
\hline Estratégias & $\begin{array}{c}\text { b) estabelecer providências dedicadas a promover a } \\
\text { capacitação permanente. }\end{array}$ \\
\hline Dificuldades/desafios & $\begin{array}{l}\text { - carência de recursos humanos qualificados; } \\
\text { - desconhecimento das potencialidades da EaD. }\end{array}$ \\
\hline
\end{tabular}

Quadro 6: Estratégias para a etapa de operacionalização e avaliação

\begin{tabular}{|c|c|}
\hline Etapa & Operacionalização/Avaliaçăo \\
\hline Grupo de incertezas & $\begin{array}{l}\text { Compromisso politico voltado ao processo de } \\
\text { EaD (G3) }\end{array}$ \\
\hline Estratégias & $\begin{array}{l}\text { a) fortalecer a integração da gestão de } \\
\text { programas diversificados e politicas em prol } \\
\text { da efetivação da EaD; } \\
\text { b) fortalecer a cooperação inter/intramunicipal } \\
\text { e estadual; } \\
\text { c) criar mecanismos que permitam a } \\
\text { autonomia financeira e de gestão até o final } \\
\text { dos empreendimentos. }\end{array}$ \\
\hline Dificuldades/desafios & $\begin{array}{l}\text { - ausência de politicas públicas estaduais e } \\
\text { municipais para EaD. }\end{array}$ \\
\hline Grupo de incertezas & $\begin{array}{l}\text { Componentes que indicam a qualidade e o } \\
\text { reconhecimento da } \mathrm{EaD}(\mathrm{G} 4)\end{array}$ \\
\hline Estratégias & a) estabelecer padrōes de qualidade. \\
\hline Dificuldades/desafios & - desconhecimento das potencialidades da EaD. \\
\hline Grupo de incertezas & Estabilidade da modalidade (G6) \\
\hline Estratégias & $\begin{array}{l}\text { a) criar mecanismos que garantam a } \\
\text { credibilidade e sustentabilidade da } \\
\text { modalidade, dando suporte politico e } \\
\text { estratégico às futuras açöes; } \\
\text { b) estabelecer parcerias que atendam às } \\
\text { demandas mais prementes e vocaçōes } \\
\text { regionais com a participaçăo da } \\
\text { comunidade, criando um processo } \\
\text { cooperativo. }\end{array}$ \\
\hline Dificuldades/desafios & $\begin{array}{l}\text { - insegurança quanto ao sucesso do } \\
\text { investimento; } \\
\text { - desconhecimento das potencialidades da EaD. }\end{array}$ \\
\hline Grupo de incertezas & Acesso e uso das NTICs (G7) \\
\hline Estratégias & $\begin{array}{l}\text { a) implementar mecanismos que concorram } \\
\text { para o aperfeiçoamento constante da } \\
\text { modalidade; } \\
\text { b) articular as lideranças locais e dos } \\
\text { dirigentes públicos, a fim de sintonizar } \\
\text { iniciativas de promoção ao acesso. }\end{array}$ \\
\hline Dificuldades/desafios & $\begin{array}{l}\text { - ausência de politicas públicas estaduais e } \\
\text { municipais para EaD. }\end{array}$ \\
\hline
\end{tabular}




\section{Referências bibliográficas}

BARCIA, R.; VIANNEY, J. Pós-graduação a distância. A construção de um modelo brasileiro. Estudos: Revista da Associação Brasileira de Mantenedores do Ensino Superior, Brasília. v. 16, n. 23, p. 51-70, nov. 1998.

BECKER, B. K.; GOMES, P. C. da C. Meio ambiente: matriz do pensamento geográfico. In: VIEIRA, P. F.; MAIMON, D. As ciências sociais e a questão ambiental: rumo à interdisciplinaridade. APED/UFPA, 1993.

CAMERON, K. Effetiteness as paradox: consensus and conflict in conceptions of o organizational effectiveness. Management Science, v. 32, n. 5, mai. 1986. Disponível em: <http://webuser.bus.umich.edu/cameronk/Effectiveness\%20as\%20Paradox.pdf>. Acesso em: 12 abr. 2005.

. Measuring organizational effectiveness in institutions of higher education. Administrative Science Quarterly, v. 23, dez. 1978. Disponível em: <http://webuser.bus.umich.edu/cameronk/Measuring\%200rg\%20Effectiveness.pdf>. Acesso em: 12 abr. 2005.

CASAS ARMENGOL, M. Universidade sin classes: educación a distancia em América Latina. Caracas: Universidad Nacional Abierta, 1987.

CORDERO, J. M. A avaliação do ensino e da aprendizagem na EAD. In: CONGRESSO BRASILEIRO DE EDUCAÇÃO SUPERIOR A DISTÂNCIA; CONGRESSO INTERNACIONAL DE EAD, 3, 2004, Rio de Janeiro. Palestra. Rio de Janeiro, 2004.

COSTA, H. B. Planejamento estratégico. Brasília: Ministério do Planejamento, Orçamento e Gestão, 2004. Disponível em: <http:/ /www.planejamento.gov.br/arquivos_down/seges/eurobrasil/planejamento_estrategico_texto.pdf>.Acesso em: 02 fev. 2005.

ELIASQUEVICI, M. K. Um modelo de avaliação integrada para análise de incertezas em programas governamentais: um estudo da educação a distância no estado do Pará. 2005. Tese (Doutorado)- Núcleo de Altos Estudos Amazônicos, Universidade Federal do Pará, 2005.

ELIASQUEVICI, M. K.; FONSECA, N. A. da. Educação a distância: orientações para o início de um percurso. Belém: Edufpa, 2004.

FUNTOWICZ, S.; RAVETZ, J. The scientific context: post normal science: a science commensurate to the questions asked? In: WALTNER-TOEWS, D.; KAY, J.; LISTER, N.-M. (Eds.). The ecosystem approach: complexity, uncertainty, and managing for sustainability. New York: Columbia University Press, 2002.

GARCIA, W. A regulamentação da educação a distância no contexto educacional brasileiro. In: PRETI, 0. (Org.). Educação a distância: construindo significados. Cuiabá: NEAD/IE - UFMT; Brasília: Plano, 2000. p. 79-88.

GARCÍA ARETIO, L. La educación a distancia: de la teoría a la prática. Barcelona: Ariel, 2001.

GALLOPÍN, G. C. et al. Science for the 21st century: from social contract to scientific core. International Journal of Social

Science, v. 168, p. 219-229, 2001. Disponível em: <http://governance.jrc.it/jrc-docs/s21c.pdf>. Acesso em: 30 nov. 2002.

KUHN, T. S. A estruturação das revoluções científicas. 2. ed. São Paulo: Perspectiva, 1978.

LITTO, F. M. Hora de recuperar o tempo perdido. Guia de educação a distância 2005. ano 2, n. 2, [2004?].

LOBO, F. S. Educação a distância: regulamentação. Brasília: Plano, 2000.

MOORE, M. G.; KEARSLEY, G. Distance education: a systems view. Belmont: Wadsworth, 1996.

MORESI, E. A. D. Delineando o valor do sistema de informação de uma organização. Ciência da Informação, Brasília, v. 29, n. 1, p. 14-24, jan./abr. 2000. Disponível em: <http://www.ibict.br/cionline/include/getdoc.php?id=592\&article=284\&mode=pdf > . Acesso em: 10 dez. 2007.

MORGAN, M. G.; HENRION, M. Uncertainty: a guide to dealing with uncertainty in quantitative risk and policy analysis. Cambridge: Cambridge University Press, 2004. 
MORIN, E. A cabeça bem-feita: repensar a reforma, reformar o pensamento. Rio de Janeiro: Bertrand Brasil, 2001.

PRADO JR., A. C. 0 processo de informatização da Universidade Federal do Pará. Belém: Edufpa, 1997, 2001. 2v.

OLIVEIRA, E. B. A análise de agrupamento aplicada ao estudo de dados sobre a educação a distância no Estado do Pará, 2005. Trabalho de Conclusão de Curso (Graduação)- Departamento de Estatística/Universidade Federal do Pará, Belém, 2005.

SUASSUMA, D. Do objetivismo à intersubjetividade: o lugar da razão na modernidade. Revista Brasileira de Pós-Graduação em Ciências Sociais. Brasília: UnB. v. 3, n. 1, 1999.

VAN ASSELT, M. B. A; ROTMANS, J. Uncertainty in integrated assessment modelling: a bridge over troubled water. Maastricht: ICIS, 2000. Disponível em: <www.icis.unimaas.nl/publ/downs/99_18.pdf>. Acesso em: 18 fev. 2002.

Recebido em 26.04.07

Aprovado em 16.06 .08

Marianne Kogut Eliasquevici, doutora em Ciências Socioambientais - NAEA/UFPA, colaboradora na assessoria de EaD da UFPA, pesquisadora do projeto Recursos Computacionais em Tecnologia da Educação, é Assessora em projetos da UFPA de EaD e professora da Faculdade de Computação da UFPA.

Arnaldo Corrêa Prado Junior, mestre em Informática - PUC/RJ, colaborador do Informam (Sistema de Informação Científica da Amazônia) da UFPA, coordenador dos projetos Portal da Amazônia: caminhando entre o rio e a floresta - UFPA - e Recursos Computacionais em Tecnologia da Educação, é professor da Faculdade de Computação da UFPA. E-mail: arnaldo@ufpa.br 